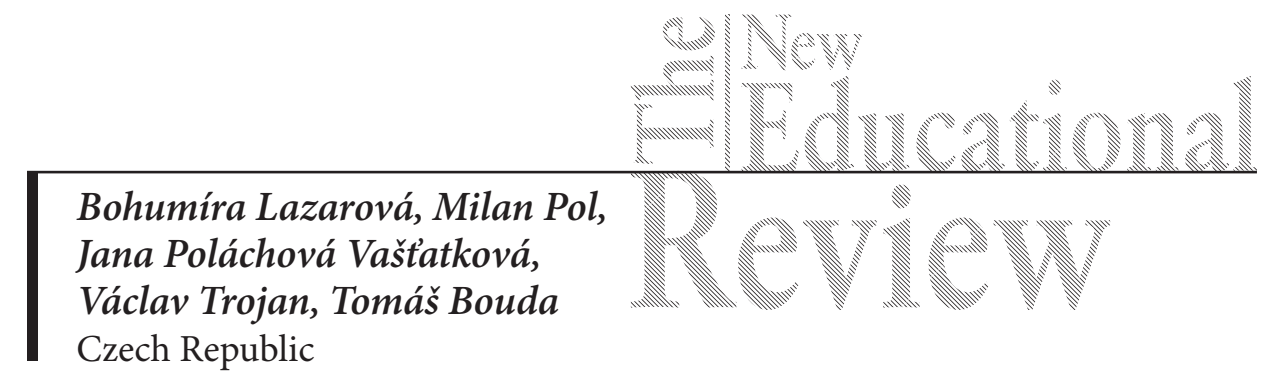

\title{
Working with Data: \\ Both an Opportunity and Challenge for School Leaders
}

DOI: $10.15804 /$ tner.2015.40.2.07

\begin{abstract}
The article analyses the concept of data, presents various purposes of working with data in schools and deals with the readiness of people at school to work with data. In the final part the article summarizes selected results of a pilot survey carried out in Czech schools and abroad, focused on finding out how and with what data schools work, which attitudes school leaders adopt towards this activity, how those respondents evaluate their own readiness for work with data and which needs they express in this respect.
\end{abstract}

Keywords: working with data, school leaders, accountability, school leadership, school development

\section{Introduction}

In many countries it has long been considered necessary to acknowledge the importance of the use of data in the operation of schools (OECD, 2007). While earlier efforts for school development were mainly based on general managerial recommendations, today the stress is on development based on concrete data, relevant for specific schools. Thus, data are a means of fulfilling the multilateral obligation of accountability and, at the same time, a source of school development (Earl, LeMahieu, 1997; Pol, 2007; Davidsdottir, Lisi, 2012; and others).

In the opening part this paper defines the term data and describes various kinds of data, the purpose of working with data and leaders' readiness to work with data in schools. Part two offers results of a pilot survey aimed at how people work with data in schools, what attitudes school leaders adopt towards this activity, how these 
respondents evaluate their own readiness for working with data. The findings are based on a survey within the DELECA project ${ }^{1}$ in the Czech Republic and partner countries (Belgium, Latvia, Slovenia and Sweden).

\section{Data and their types}

In brief terms and in a very broad sense, data can be understood as information systematically collected and arranged, be it in the form of words, numbers or other forms. Therefore, data can be of both quantitative and qualitative nature.

Data may adopt a large variety of forms, which do not only relate to students' results being the most important indicators of the quality of a school. In fact, data is what schools should use to prove convincingly that they work well. Schools should thus know how to search for and utilize suitable data (from outside) for their development. At the same time, they are expected to collect data on themselves and use them to develop and present their own work (cf. Pol, 2007). Therefore, not only do data serve for planning school development, but they are an indicator of school quality.

Bernhardt (2004) identifies four fields where it is important for schools to work with data. These are (1) demographic data (enrolled students, attendance, premature departure, ethnicity, gender, etc.), (2) the process of education and schooling (description of the curriculum and the main processes related to its development), (3) students' learning and results (results of standardized tests, norms, criteria, evaluation, etc.) and (4) the approach to pedagogical work (how education and learning are perceived, what values, beliefs and teachers' attitudes there are etc.). Nevertheless, the data from these fields must be perceived in their mutual relations, connections and intersections. Copland et al. (2009) add to demographic data on student learning and school processes also perception of the learning environment, values, teachers' characteristics, job description, qualifications, participation in in-service training, etc. It is these areas which the research within the DELECA project was based on, as well.

\section{Internal development and external control}

By distinguishing between data collection aimed at students' results and other areas of school operation, Verbiest \& Mahieu (2013) offer four points of view of the use of data. Data can be used (1) from the viewpoint of accountability, focusing

${ }^{1}$ www.deleca.org 
on students' results; (2) from the viewpoint of accountability, focusing on school operation; (3) from the viewpoint of development, focusing on students' results; and (4) from the viewpoint of development, focusing on the school. These different views require the collection and interpretation of different types of data. For the sake of accountability, students' results are especially important, while the viewpoints of development put more stress on data covering the impact of organizational conditions on students' learning. The views mentioned, seemingly diverse, in many respects overlap. For instance, schools can collect, interpret and use data to improve both students' results and school operation. Therefore, they can interconnect the prospect of accountability and that of development, use data to present educational and other work to people externally involved and, at the same time, use them as a source for development (Davidsdottir \& Lisi, 2012; Dvořák, 2012).

\section{Readiness for work with data}

For these reasons, school leaders are expected to be able to collect data, understand them and use them in a critical and detached view (cf. Copland et al, 2009). Nevertheless, the point is not only the readiness of individuals. There is a growing call for school culture, a strong feature of which is working with data (Hargreaves, 1996; Earl \& Katz, 2006).

Vanhoof et al. (2013) pinpoint various competences in relation to particular stages of working with data. At the opening stage it is the collection (search), study and discussion of data aimed at their correct interpretation. Then there is the stage of use, including the determination of needs, planning, implementation of change and evaluation. The emphasis on the distinction between interpretation of data and their use is a consequence of the discovery that the shift from data interpretation to planning of changes and materialization of measures in schools is often protracted. In their data-based judgment, school leaders must be restrained and sensitive to the multiple meaning of interpretations (Earl \& Katz, 2006).

\section{$\underline{\text { Research methodology }}$}

In order to support school leaders' training in working with data, the abovementioned DELECA project started in 2012. One of the specific goals of the project was the creation of a training program curriculum for school leaders. This program should help school leaders to (a) gain an overview of the principal resources of data which are useful for learning and school development, 
(b) improve their ability to understand such data and (c) improve their readiness to work with these data in order to aid school development.

First it was necessary to create a clearer idea about how schools should work with certain data, what attitudes school leaders adopt towards these issues, how they evaluate their own abilities to work with data and which educational needs they have in this respect. For this, an on-line questionnaire was constructed and distributed to all current participants of educational leadership programs (compulsory functional education) in 2013 at the Faculty of Arts of Masaryk University, Brno, and the Faculties of Education at the Universities of Olomouc, Ostrava and Prague. We addressed higher education workplaces offering this type of training and willing to cooperate in data collection. The method of data collection provided for an almost 100\% return rate. The leaders of the three different levels of schools with different lengths of both teacher and leadership experience (e.g. as deputy head teachers) were represented in the group of respondents. The conclusions of the survey are undoubtedly significant (even though they cannot be generalized). Only selected results from the pilot survey are mentioned in this article, indicating roughly which data Czech schools work with and the opinion school leaders have on this subject. A total of 171 questionnaires from school leaders were processed; $52 \%$ of them from basic schools (ISCED $1+2$ ), $24 \%$ from secondary schools (ISCED 3) and 24\% from nursery schools (ISCED 0), of which 121 were submitted by female respondents. Seven questionnaires were removed because of incompleteness. Because of difficult comparability of data from various levels of schools we present the results for all the schools together. Yet, it is necessary to mention that the differences among school levels were insignificant and we only remark on certain trends in different behaviour of schools as indicated by the data.

\section{How do Czech schools work with data? Results and Discussion}

First we asked the respondents which types of data they usually work with at schools and which data on their schools they collect and for what purpose. The results prove the prevailing interest in data related to students' educational process (attendance, premature departure, results) while the least interest is in data on the outside environment and how the milieu of the school is perceived by various subjects (Figure 1).

As for the purpose of data collection, the respondents are more biased to the purpose of the cognition of their schools and their development rather than accountability. Yet, it is evident that the importance of data in terms of account- 
ability grows with the level of the school. Secondary schools, which perhaps have to struggle more for students than others, make more effort to collect data through which they can present themselves positively on the outside (Figure 2).

Figure 1. Types of data and the extent of data collection in schools

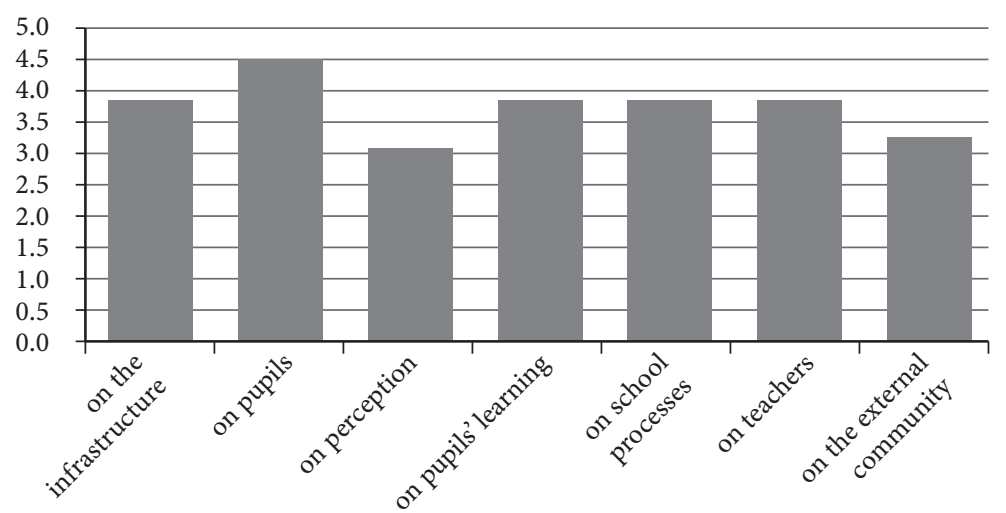

Scale used: $1=$ not at all; 5 = yes, in full; the diagram represents mean values.

Questionnaire items in this field:

on the infrastructure of the institution (buildings, environs, ownership, etc.); on pupils (enrolment, attendance, early departure from school, ethnicity, gender, etc.); on perception (of the school milieu, of values and beliefs, of opinions and attitudes, etc.); on pupils' learning (tests, fulfilment of criteria, capabilities for study and learning habits, etc.); on school processes (educational programme, didactic strategies, etc.); on teachers (teachers' tasks, qualifications, mobility, professional development, etc.); on the external community (parents, local community, etc.)

Figure 2. Purpose of data collection

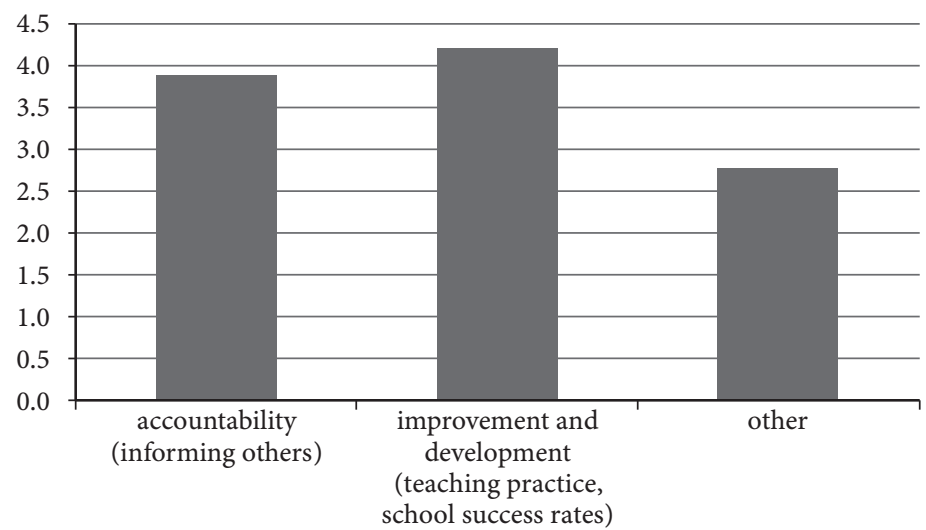

Scale used: $1=$ do not agree at all; 5 = fully agree; the diagram represents the mean values. 
Another part of the questionnaire was aimed at particular activities comprising work with data (data collection, data analysis and interpretation, data handling and statistics, work with diagrams and tables, executing a survey, use of data for decision-making in education and use of data for school development). The first question asked about the extent to which the respondents considered particular activities in working with data as their own tasks. The results indicate that they consider it their task and duty to handle data and use them for decision-making and school development, but they consider it less to be their duty to collect data and, for this purpose, carry out surveys. It is more evident with secondary school representatives. Undoubtedly, such perception has much to do with real life and a certain unwillingness to collect data in one's own school and execute surveys for this purpose (cf. Figures 3 a 4 ). The respondents say that they use data mostly for decision-making and school development and try to analyse and interpret them, but, again, they pay much less attention to data collection and surveys in their own schools.

There may also be the feeling of a lack of time for such activities. In her research, Prášilová (2011) shows that school leaders are overloaded with administrative operations and their chances to engage in the management of educational work and other activities are limited.

Figure 3. Work with data - reality

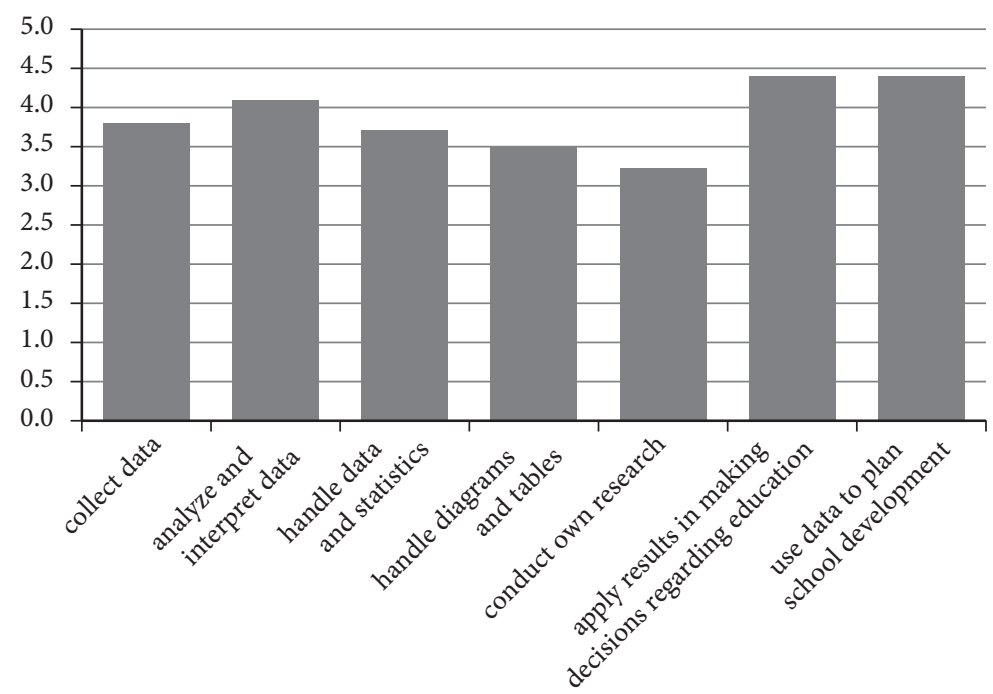

Scale used: $1=$ do not agree at all; $5=$ fully agree; the diagram represents the mean values. 
Figure 4 indicates the same trend, which is the highest willingness to use data for decision-making and the development of the school. This trend is most significant with regard to basic and secondary schools, while the respondents from nursery schools tend slightly more to place emphasis on data collection and execution of their own surveys. These findings may be interpreted in relation to the demographic development and the current situation in the network of schools where, in general terms, nursery schools do not face such strong competition.

Figure 4. Work with data - willingness

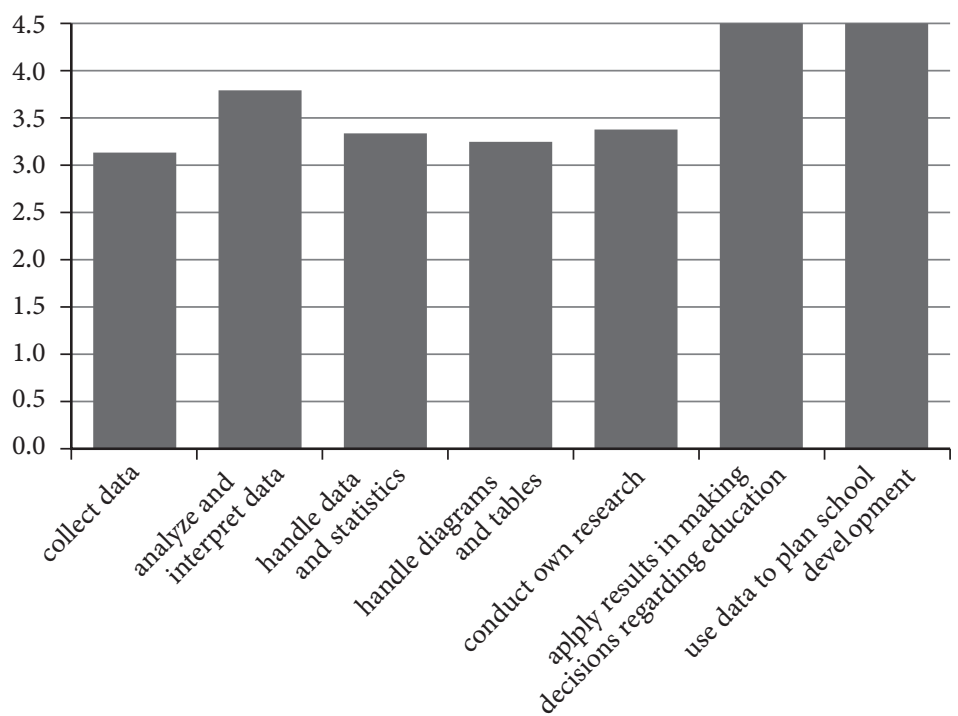

Scale used: $1=$ do not agree at all; 5 = fully agree; the diagram represents the mean values.

In the final part of the questionnaire we asked the respondents to estimate their own ability to work with data (for the sake of simplicity we did not distinguish between knowledge, abilities and skills). The respondents consider themselves least competent in carrying out surveys in their own schools (Figure 5). Unlike this activity they consider themselves quite competent in other activities connected to work with data. They are most self-confident in the use of data for decisionmaking and school development; the leaders at basic schools believe a little more strongly that they are able to handle data and statistics as well as carry out their own research. Somewhat surprisingly for us, the need for in-service training (Figure 6) was expressed as relatively weak by the leaders of all types of schools. 
Slightly more interest in such education is shown by the respondents in nursery schools, which is then logically reflected in the results of gender categorization indicating more motivation for work with data and education in this field among the female head teachers.

Figure 5. Work with data - perceived ability

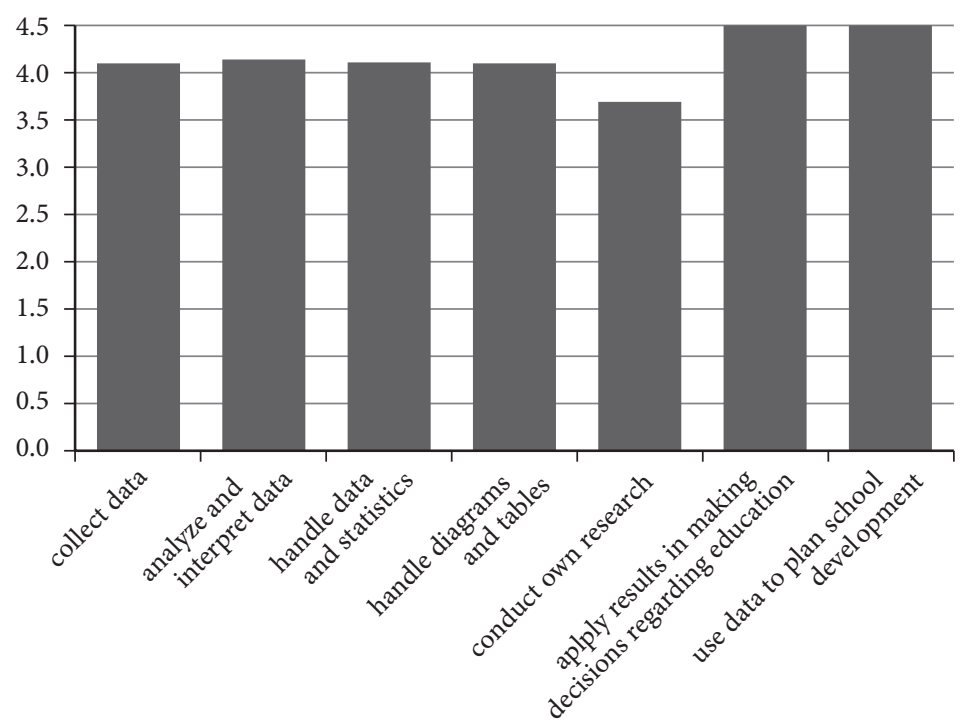

Scale used: $1=$ not at all; $5=$ fully; the diagram represents the mean values.

From the items in particular areas of the questionnaire we counted summation indices expressing the mean values of the summation of answers. This procedure enabled us to compare the participating countries as for the respondents' tendency to engage in various fields of work with data and their estimation of their abilities and educational needs.

- The Index of Data collection expresses the extent to which schools, according to the respondents, collect data in particular areas of the school operation ( 8 items; item others was removed because of insufficient number of options, cf. Figure 1).

- The Index of Working with data expresses the extent to which the respondents engage in selected tasks connected to working with data (4 items). ${ }^{2}$

\footnotetext{
${ }^{2}$ Items: You look for and collect data; You plan your time to work with data; You develop the culture of data use; You involve employees or other important persons.
} 
Figure 6. Work with data - expressed training needs

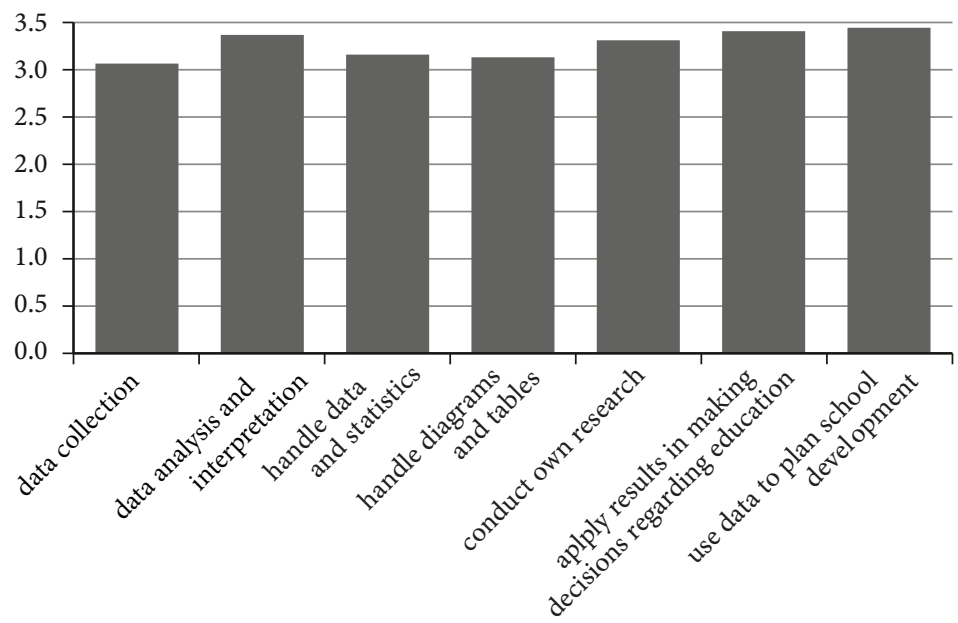

Scale used: $1=$ not at all; 5 = fully; the diagram represents the mean values.

Comparison of summation indices by participating countries

- The Index of Leaders' tasks expresses the extent to which the respondents consider particular activities in working with data as their task or duty (7 items).

- The Index of Reality expresses the extent to which these activities are carried out in the real life of the school (7 items, cf. Figure 3).

- The Index of Willingness expresses the extent of the willingness of the respondents to work with data; in other words to carry out particular activities working with data ( 7 items, cf. Figure 4 ).

- The Index of Ability expresses the evaluation of the respondents' own skills in particular activities in working with data (7 items, cf. Figure 5).

- The Index of Training needs expresses the extent of the respondents' needs to learn to work with data (7 items, cf. Figure 6).

Using a statistical test (Cronbach alpha) we discovered high inner consistence with the indices, featuring values between 0.81 and 0.90 .

The indices show (Table 2) more clearly that the respondents express the highest affirmation in their perception of their duty to work with data and evaluate their skills in this field. The lowest affirmation is expressed for items inquiring about educational needs. The lowest need to educate oneself in working with data is felt by 
Table 2. Summation indices

\begin{tabular}{lcc}
\hline \multicolumn{1}{c}{ Field } & $\begin{array}{c}\text { total } \\
\text { average }\end{array}$ & $\begin{array}{c}\text { standard } \\
\text { deviations }\end{array}$ \\
\hline I - Data collection & 3.8 & 0.8 \\
\hline I - Working with data & 3.5 & 0.8 \\
\hline I - Leaders' tasks & 4.2 & 0.6 \\
\hline I - Reality & 3.9 & 0.7 \\
\hline I - Willingness & 3,7 & 0.8 \\
\hline I - Ability & 4,2 & 0.7 \\
\hline I - Training needs & 3,3 & 1.0 \\
\hline
\end{tabular}

basic school leaders (3.11). Simultaneously, these people evaluate themselves as the most capable (4.24). On the contrary, nursery school leaders feel the highest need to educate themselves (3.56). It must be remarked, though, that the Index of Training needs is where the highest standard deviation was found (0.98). By contrast, most conformity was shown by the respondents for leaders' tasks (standard deviation 0.62). The need for education in working with data, as felt by the respondents, is most probably related to the attitudes expressed: if leaders do not intend to work with data, logically their need to educate themselves in this field is not so strong.

Let us finally highlight some of the findings in Czech schools that were different from those in other participating countries in the DELECA project. Our foreign partners carried out the same survey with participants in in-service training for school leaders. Aware of the nature and size of the sets surveyed, we do not want to draw unequivocal conclusions from such comparisons, but our objective is to point out certain differences in the results. Table 3 shows that the Czech school leaders adopt less positive attitudes to working with data (in relative terms), express a lower need to further educate themselves in this field (in relative terms again), but contrary to this, they assess their skills somewhat higher.

Table 3. International comparison of indices (all school levels: nursery, basic, secondary)

\begin{tabular}{lcccccc}
\hline & $\mathrm{BE}$ & $\mathrm{CZ}$ & $\mathrm{LV}$ & $\mathrm{SE}$ & $\mathrm{SI}$ & total \\
\hline Index of Data collection & 3.3 & 3.8 & 3.9 & 3.2 & 3.8 & 3.6 \\
\hline Index of Working with data & 3.1 & 3.5 & 3.8 & 3.0 & 3.6 & 3.5 \\
\hline Index of Leaders' tasks & 3.8 & 4.2 & 4.4 & 4.0 & 4.1 & 4.1 \\
\hline Index of Reality & 3.3 & 3.9 & 4.1 & 3.4 & 4.1 & 3.8 \\
\hline
\end{tabular}




\begin{tabular}{lcccccc}
\hline & BE & CZ & LV & SE & SI & total \\
\hline Index of Willingness & 3.9 & 3.7 & 4.4 & 4.0 & 4.2 & 4.1 \\
\hline Index of Ability & 3.8 & 4.2 & 4.3 & 3.9 & 4.1 & 4.1 \\
\hline Index of Training needs & 3.6 & 3.3 & 3.3 & 3.3 & 3.8 & 3.4 \\
\hline
\end{tabular}

The diagram represents mean values; $B E=$ Belgium; $C Z=$ Czech Republic; $L V=$ Latvia; $S E=$ Sweden $;$ SI = Slovenia .

For all the countries the index of educational needs shows the lowest values. However, we realize the limits of our survey. For instance, for the self-evaluation of skills in working with data, the respondents may have varying ideas concerning what such work requires if truly appropriate results are expected.

\section{Conclusion}

In today's environment, which rather suffers from a glut in data, working with data is a subject that requires attention. To work with data requires specific knowledge as well as skills and attitudes. Our pilot survey shows that school leaders look at working with data in quite a positive way: they say they usually work with data and consider working with data to be their task.

Since the respondents were addressed on-line, thus in a fully anonymous manner, there is no reason to suspect them of being forced to comply with what is required from the outside or regarded as positive value. The credibility is even more enhanced by the fact that the respondents confess to mediocrity in their willingness to work with data and, equally, in their interest in the respective training. Our questionnaire survey could not, and did not, provide a profound insight into the reality of working with data in schools. Nevertheless, the results clearly show which activities in working with data are more appealing to school leaders and what purposes they use data for, and what purposes they would want to use data for.

It is also necessary to mention that school leaders often face a difficult task: according to research, teachers do not feel the need to rely on data in their decision-making, believing that their experience is sufficient for high-quality decisions (Schildkamp, Kuiper, 2010). Therefore, the head teacher becomes a model and, at the same time, a creator and supporter of school culture in which working with data thrives. The results show a certain hesitation of head teachers, mainly in carrying out practical research. However, practical research is what brings evidence of the efficiency of school interventions. In this respect, it is not only desirable to 
educate people in schools in the field of working with data but also to interconnect more strongly the academic sphere (in other words, departments strong in methodology) with practical life in schools.

We are aware of the fact that this pilot survey has its limits. Undoubtedly, the respondents varied a lot in their ideas about what working with data consists in and what it means to be competent in working with data. There is little to be gained by further analysing and interpreting the differences in terms of the various levels of schools, gender, length of experience or differences among partner countries, nor is it meaningful to test the statistical significance of these differences. Our pilot survey can be considered as a good basis for creating the Working with data training modules and, at the same time, inspiration for subsequent questions and hypotheses to be potentially verified in future research.

\section{Acknowledgement:}

The text was created within the Comenius project DELECA (Developing leadership capacity for data-informed school improvement); No. 526499-LPP-1-2012-1-SI-COMENIUS-CMP

\section{References}

Bernhardt, V. (2004). Data analysis for continuous school improvement. Larchmont, NY: Eye on Education.

Copland, M., Knapp, M., \& Swinnerton, J. (2009). Principal leadership, data and school improvement. In: T. Kowalski \& T. Lasley (Eds.), Handbook of data-based decision making in education (s. 153-172). New York: Routledge.

Davidsdottir, S. \& Lisi, P. (2012). Spolupráce učitelů a jak ji podněcovat (poznatky z longitudinální a průřezové studie interní evaluace na Islandu). Studia paedagogica, 17(2), 51-70.

Dvořák, D. (2012). Nový institucionalismus v pedagogice. Studia paedagogica, 17(2), 9-26.

Earl, L., \& Katz, S. (2006). Leading schools in a data-rich world. Harnessing data for school improvement. Thousand Oaks: Corwin Press.

Earl, L., \& LeMahieu, P. (1997). Rethinking assessment and accountability. In Hargreaves, A. (ed.) Rethinking educational change with heath and mind: 1997 ASCD Yearbook (pp. 149-168). Alexandria VA: Association for Supervision and Curriculum Development.

Hall, G., \& Hord, S. (2006). Implementing change: patterns, principles and potholes ( $\left.2^{\text {nd }} \mathrm{ed}.\right)$. Boston: Pearson Education.

Hargreaves, D. (1996) Teaching as a reseach-based profession: possibilities and prospects. London: Teacher Training Agency.

Kowalski, T. (2009). Evidence and decision making in professions. In T. Kowalski \& T. Las- 
ley (Eds.), Handbook of data-based decision making in education (pp. 3-19). New York: Routledge.

OECD (2007). Evidence in education: Linking research and policy. Paris: OECD.

Pol, M. (2007). Škola v proměnách. Brno: Masarykova univerzita.

Prášilová, M. (2011). Profesní rozvoj ředitelư českých škol. Olomouc: PdF UP.

Schildkamp, K., \& Kuiper, W. (2010). Data-informed curriculum reform: Which data, what purposes, and promoting and hindering factors. Teaching and Teacher Education, 26(3), 482-496.

Vanhoof, J., Verhaeghe, G., Van Petegem, P., \& Valcke, M. (2013). Improving data literacy in schools : lessons from the school feedback project. In K. Schildkamp, M.K. Lai \& L. Earl (Eds.), Data-based decision making in education: challenges and opportunities (pp. 113-134). Dordrecht: Springer.

Verbiest, E., \& Mahieu, P. (2013). Developing leadership capacity for data-informed school improvement (DELECA). Theoretical framework. Available at http://www.deleca.org. 